\title{
CD24 Modulates Chemosensitivity of MCF-7 Breast Cancer Cells
}

\author{
HIDEYA ONISHI ${ }^{1}$, KUMI SUYAMA $^{1}$, AKIO YAMASAKI ${ }^{1}$, YASUHIRO OYAMA ${ }^{1}$, \\ AKIKO FUJIMURA $^{1}$, MAKOTO KAWAMOTO ${ }^{1}$ and AKIRA IMAIZUMI ${ }^{2}$ \\ ${ }^{1}$ Department of Cancer Therapy and Research, \\ Graduate School of Medical Sciences, Kyushu University, Fukuoka, Japan; \\ ${ }^{2}$ Shukoukai Inc., Tokyo, Japan
}

\begin{abstract}
The role of cluster of differentiation (CD) 24 in breast cancer remains unclear; previously, we showed that CD24 suppresses malignant phenotypes by inactivating Hedgehog signaling through signal transducer and activator of transcription (STAT) 1 inhibition. In this study, we examined how CD24 affects chemosensitivity in breast cancer cells. The $C D 44^{+} C D 24^{+}$breast cancer cell line MCF-7 was transfected with CD24 with/without STAT1 siRNA, and chemosensitivity to 5-fluorouracil (5-FU) and cis-diamminedichloroplatinum (CDDP) was measured. CD24 inhibition reduced chemosensitivity to 5-FU, while STAT1 inhibition did not affect chemosensitivity to 5-FU in CD24 siRNA-transfected cells. Conversely, CD24 inhibition did not affect chemosensitivity to $C D D P$, while STAT1 inhibition reduced chemosensitivity to CDDP in CD24 siRNA-transfected cells. STAT1 inhibition, but not CD24 inhibition, reduced expression of the ATP-binding cassette $(A B C)$ transporter genes, $A B C B 1$ and $A B C G 2$. In conclusion, $C D 24$ inhibition may modulate chemosensitivity according to drug type, but $A B C$ transporter expression appears not to contribute to this mechanism. This study contributes to determining the role of CD24 in breast cancer.
\end{abstract}

Since the identification of cancer stem cells (CSCs) in breast cancer (1), there has been a focus on the biological phenotypes of cluster of differentiation (CD) $24^{-/ 10 w} \mathrm{CD} 44^{+}$ cells. However, the biological role of CD24 remains unclear, and how CD24 status affects chemosensitivity also remains controversial (2-5). We previously showed that CD24 regulates proliferation and invasion via signal transducer and

Correspondence to: Hideya Onishi, Department of Cancer Therapy and Research, Graduate School of Medical Sciences, Kyushu University, Fukuoka 812-8502, Japan. Tel: +81 926426220, Fax: +81926426221, e-mail: ohnishi@surg1.med.kyushu-u.ac.jp

Key Words: CD24, chemosensitivity, MCF-7 cells, breast cancer, cancer stem cell. activator of transcription (STAT) 1 inhibition, which inactivates Hedgehog (Hh) signaling in breast cancer, and that STAT1 could be a therapeutic target (6). We also revealed that Hh signaling plays an important role in the maintenance of the $\mathrm{CD} 24^{-/{ }^{\text {low }} \mathrm{CD}} 44^{+}$population of breast cancer cells (7). Many researchers have also shown a relationship between the $\mathrm{CD} 24^{-/ \text {low }} \mathrm{CD} 44^{+}$population and Hh signaling (8-10). Apart from regulating phenotypic changes, chemosensitivity is also an important factor for cancer treatment. ATP-binding cassette (ABC) transporters, such as $\mathrm{ABCB} 1$ and $\mathrm{ABCG}$, are thought to be activated in CSCs and contribute to multidrug-resistance phenotypes $(11,12)$. In this study, we examined how CD24 affects chemosensitivity in breast cancer cells.

\section{Materials and Methods}

Cell culture and reagents. Human breast cancer MCF-7 cell line (American Type Culture Collection, Manassas, VA, USA) was maintained in RPMI-1640 medium (Nacalai Tesque, Kyoto, Japan) supplemented with $10 \%$ fetal calf serum (FCS; Life Technologies Grand Island, NY, USA), and antibiotics (100 units/ml of penicillin and $100 \mu \mathrm{g} / \mathrm{ml}$ of streptomycin; Meijiseika, Tokyo, Japan). 5Fluorouracil (5-FU) and cis-diamminedichloroplatinum (CDDP) were purchased from Kyowahakkou Kirin (Tokyo, Japan) and Bristol Myers Squibb (New York, NY, USA), respectively. The concentration of 5-FU and CDDP used in experiments was determined according to previous research (13).

RNA interference. Small interfering RNA (SiRNA) for CD24 (ONTARGETplus $^{\text {TM }}$ SMART pool, L-187156), STAT1 (ONTARGETplus $^{\text {TM }}$ SMART pool, L-003543), and negative control (ON-TARGETplus ${ }^{\text {TM }}$ Control Non-targeting siRNA, D-001810) were purchased from Dharmacon RNA Technologies (Chicago, IL, USA). Cells $\left(0.2 \times 10^{6}\right.$ cells/well $)$ seeded in 6 -well plates were transfected with $100 \mathrm{nM}$ siRNA using Lipofectamine RNAiMax Reagent (Invitrogen, Carlsbad, CA, USA) according to the manufacturer's instructions. Cells were used for experiments at 2 days after transfection.

Real-time reverse-transcription ( $R T)$ - polymerase chain reaction $(P C R)$. Total RNA was extracted using High Pure RNA Isolation kit 
(Roche Diagnostics Gmbh, Mannheim, Germany). For real-time RTPCR, $1 \mu \mathrm{g}$ of RNA was treated with DNase and was reverse transcribed to cDNA using the Quantitect Reverse Transcription Kit (Qiagen, Valencia, CA, USA). Reactions were run with $\mathrm{iQ}^{\mathrm{TM}} \mathrm{SYBR}$ Green Supermix (Bio-Rad, Hercules, CA, USA), on a DNA Engine Option 2 System (MJ Research, Waltham, MA). The primer sequences used were $A B C B 1$, forward, 5'-TGA CAT TTA TTC AAA GTT AAA AGC A-3', reverse, 5'-TAG ACA CTT TAT GCA AAC ATT TCA A-3'; ABCG2, forward, 5'-GCC GTG GAA CTC TTT GTG GTA G-3', reverse, 5'-ACA GC AAG ATG CAA TGG TTG T-3', and $\beta$-actin (ACTB), forward, 5'-TTGCCGACAGGA TGCAGAAGGA-3', reverse, 5'-AGGTGGACAGCGAGGCCAGG AT-3'. The amount of each target gene in a given sample was normalized to the level of $A C T B$.

Fluorescence-activated cell sorting (FACS) analysis. To analyze the expression of the surface molecules on MCF-7 cells, cells were incubated for $30 \mathrm{~min}$ with fluorescein isothiocyanate-conjugated monoclonal antibody to CD24 (BD Pharmingen, San Diego, CA, USA) and phycoerythrin (PE)-conjugated antibody to CD44 (BD Pharmingen). Mouse IgG was used as isotype controls (BD Pharmingen). The fluorescence intensity was measured using a FACSCalibur flow cytometer (BD Pharmingen) and analyzed with CELLQuest software (BD Pharmingen).

Statistical analysis. Data are presented as the means \pm standard deviation (SD). Student's $t$-test was used to compare continuous variables between two groups. A $p$-value of less than 0.05 was considered statistically significant.

\section{Results}

CD24 inhibition reduced chemosensitivity of $M C F-7$ cells to 5-FU. Since the MCF-7 cell line primarily consists of $\mathrm{CD} 24^{+}$ cells, MCF-7 cells were selected for this study. We first confirmed that transfection of MCF-7 cells with CD24 siRNA significantly reduced CD24 expression (Figure 1). Next, chemosensitivity to 5-FU was measured in control MCF-7 cells, CD24 siRNA-transfected MCF-7 cells and CD24 and STAT1 siRNA-co-transfected MCF-7 cells. 5-FU chemosensitivity of $C D 24$ siRNA-transfected MCF-7 cells was significantly lower compared to control cells on both day 1 and 2 (Figure 2). STAT1 inhibition did not significantly affect chemosensitivity to $5-\mathrm{FU}$ of $\mathrm{CD} 24$ siRNA-transfected MCF-7 cells (Figure 2).

CD24 inhibition did not affect chemosensitivity to CDDP in $M C F-7$ cells. Next, the chemosensitivity to CDDP was investigated in the same cells. While chemosensitivity to CDDP in CD24 siRNA-transfected MCF-7 cells increased compared with controls on day 1 , there was no significant difference in chemosensitivity on day 2 (Figure 3). STAT1 inhibition significantly reduced chemosensitivity to CDDP in CD24 siRNA-transfected MCF-7 cells (Figure 3).

STAT1 inhibition but not CD24 inhibition decreased ABCB1 and $A B C G 2$ expression. $A B C B 1$ and $A B C G 2$ are involved in
MCF-7 cells

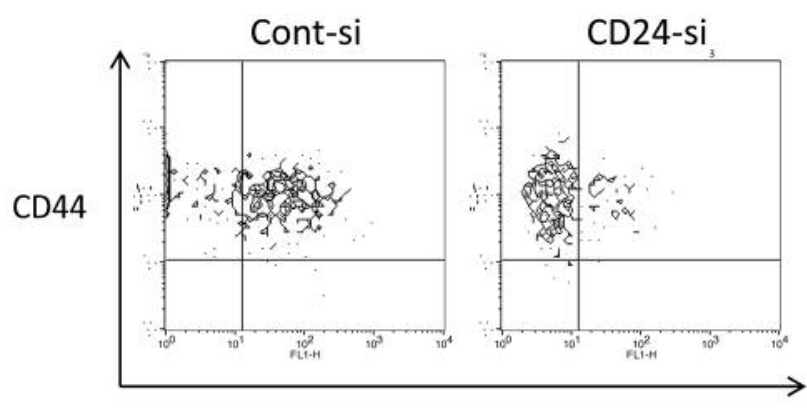

$\mathrm{CD} 24$

Figure 1. Expressions of cluster of differentiation (CD) 24 and CD44 on control (Cont) siRNA- and CD24 siRNA-transfected MCF-7 cells were investigated by fluorescence-activated cell sorting analysis.

drug resistance, playing pivotal roles in efflux of chemotherapeutic drugs (14-16). Therefore, expression of $A B C B 1$ and $A B C G 2$ in control siRNA, CD24 siRNAtransfected and $C D 24$ and STAT1 siRNA-co-transfected MCF-7 cells was measured. There was no significant change in $A B C B 1$ and $A B C G 2$ mRNA expression in $C D 24$ siRNAtransfected MCF-7 cells compared with control cells. However, expression of $A B C B 1$ and $A B C G 2$ in CD24 and STAT1 siRNA-co-transfected MCF-7 cells significantly decreased compared with CD24 siRNA-transfected MCF7cells (Figure 4).

\section{Discussion}

In this study, STAT1 inhibition led to a decrease in $A B C B 1$ and $A B C G 2$ expression in CD24-inhibited MCF-7 cells. An augmentation of chemosensitivity is anticipated in this situation; however, chemosensitivity to 5-FU did not increase, and conversely, chemosensitivity to CDDP decreased (Figures 2 and 3). One potential mechanism for these results is that the percentage of cells in $\mathrm{S}$ phase might be decreased by $\mathrm{Hh}$ signaling inactivation, which results from STAT1 inhibition; 5-FU is an $\mathrm{S}$ phase-sensitive drug, and therefore may not have been as active, as was previously shown (13). Our results are consistent with the findings of Kaewpiboon et al. who showed that STATl up-regulation affects etoposide resistance through $A B C B 1$ expression (17). The activity of $\mathrm{ABC}$ transporters may differ depending on drug type. CDDP is a cell cycle-independent drug, and we have no clear hypothesis regarding why chemosensitivity to CDDP did not increase concomitantly with decreasing $\mathrm{ABC}$ transporter expression. There may be other genes or molecules that were affected by STAT1 inhibition. Furthermore, STAT1 inhibition has been shown to reduce proliferation of and invasion by 


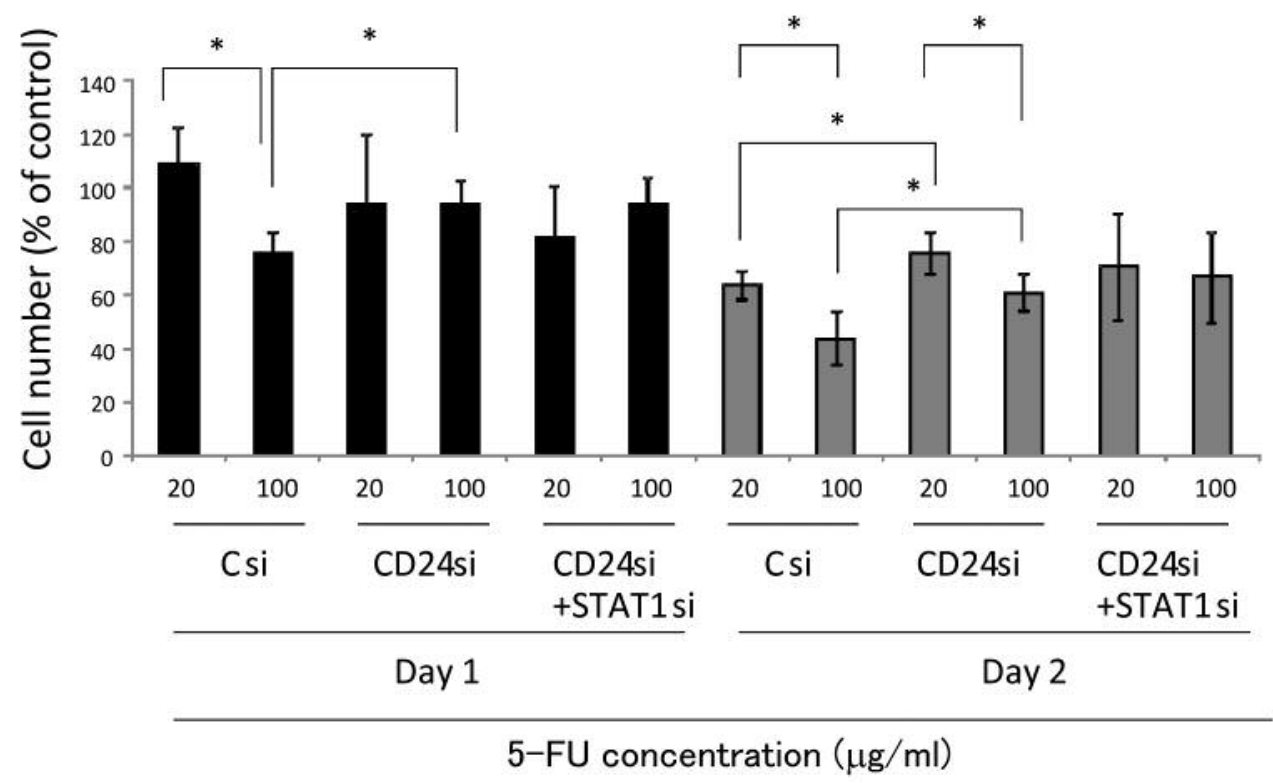

Figure 2. MCF-7 cells transfected with control siRNA (C si), CD24 siRNA, and both CD24 and STAT1 siRNA were treated with 5-fluorouracil (5$F U)$ at the indicated concentration. After 1 and 2 days' culture, viable cells were counted under light microscopJ. *Significantly different at $p<0.05$.

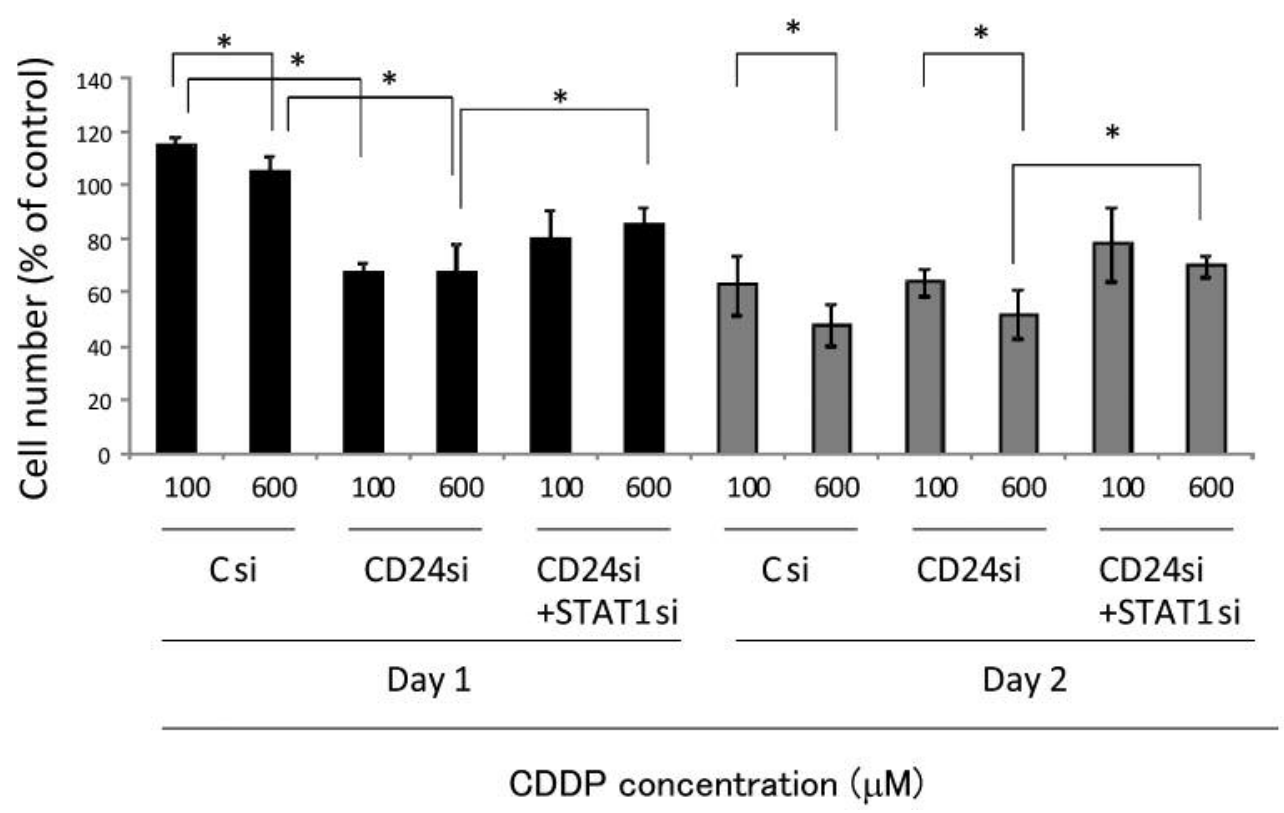

Figure 3. MCF-7 cells transfected with control siRNA (C si), CD24 siRNA, and both CD24 and STAT1 siRNA were treated with cisdiamminedichloroplatinum $(C D D P)$ at the indicated concentration. After 1 and 2 days' culture, viable cells were counted under light microscopy. *Significantly different at $p<0.05$.

MCF-7 cells (6). Therefore, STAT1 may be a therapeutic target in breast cancer, but we caution should be exercised in cases of combination chemotherapy.

Importantly, the $\mathrm{CD} 24^{-/ \mathrm{low}} \mathrm{CD} 44^{+}$population itself are not breast CSCs; breast CSCs cannot be induced by CD24 inhibition alone. Indeed, not all Hs578T cells, which are mainly CD24-, have stem cell-like features (6). Whether the relationship between CD24 expression and various pathological features or cell phenotypic changes is causal or the result of indirect interactions should be carefully studied. 
$A B C B 1$ mRNA

A

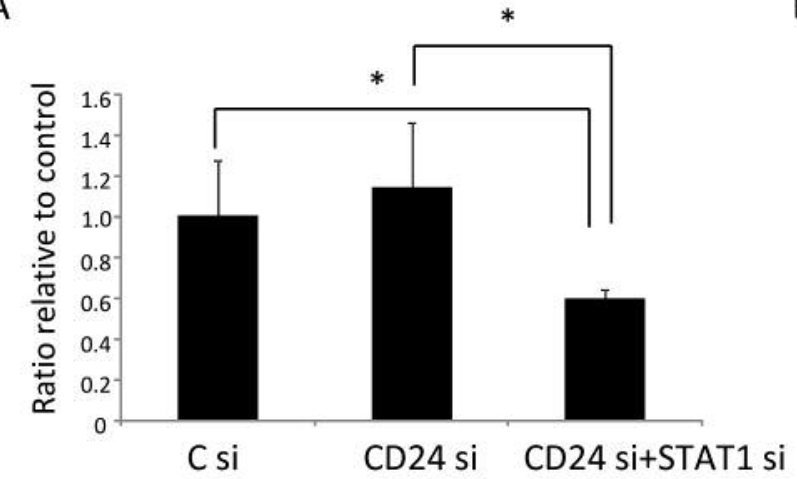

B

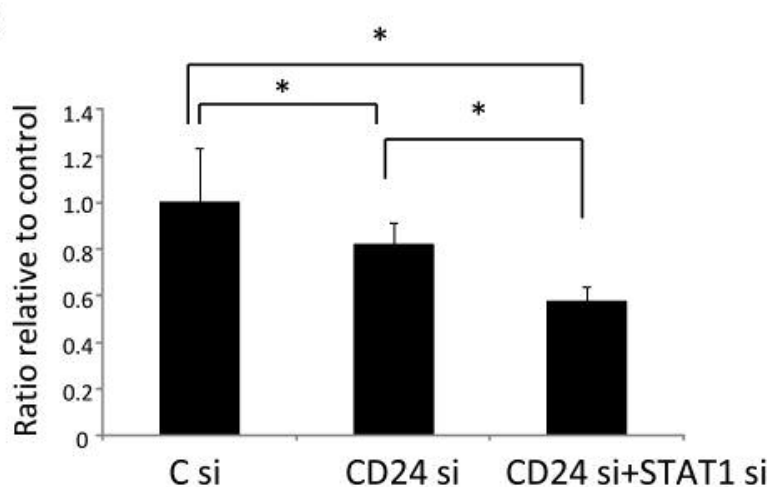

Figure 4. ATP-binding cassette sub-family B member $(A B C B) 1$ (A) and ABCG2 (B) mRNA expression in MCF-7 cells transfected with control siRNA (C si), CD24 siRNA, and both CD24 and STAT1 siRNA were estimated by real-time polymerase chain reaction. *Significantly different at $p<0.05$.

In conclusion, we examined the role of $\mathrm{CD} 24$ in breast cancer cells, especially focusing on chemosensitivity. CD24 inhibition may modulate chemosensitivity according to drug type, and $\mathrm{ABC}$ transporter expression might not contribute to the molecular mechanism involved in this. This study helps determine the cellular function of $\mathrm{CD} 24$ in breast cancer and breast CSCs.

\section{Conflicts of Interest}

The Authors declare no conflict of interest in regard to this work.

\section{Acknowledgements}

This study was supported by the Japan Society for the Promotion of Science Kakenhi Grant Number JP26293289. The Authors thank Ms Kaori Nomiyama for skillful technical assistance.

\section{References}

1 Al-Hajj M, Wicha MS, Benito-Hernandez A, Morrison SJ and Clarke MF: Prospective identification of tumorigenic breast cancer cells. Proc Natl Acad Sci USA 100: 6890, 2003.

2 Zhou X: CD24 polymorphisms cannot predict pathologic complete response to anthracycline- and taxane-based neoadjuvant chemotherapy in breast cancer. Clin Breast Cancer 14: e33-40, 2014.

3 Kwon MJ, Han J, Seo JH, Song K, Jeong HM, Choi JS, Kim YJ, Lee SH, Choi YL and Shin YK: CD24 Overexpression is associated with poor prognosis in luminal A and triple-negative breast cancer. PLoS One 10: e0139112, 2015.

4 Chen Y, Song J, Jiang Y, Yu C and Ma Z: Predictive value of CD44 and CD24 for prognosis and chemotherapy response in invasive breast ductal carcinoma. Int J Clin Exp Pathol 8: 1128711295, 2015.
5 Ji P, Zhang Y, Wang SJ, Ge HL, Zhao GP, Xu YC and Wang Y: CD44hiCD24lo mammosphere-forming cells from primary breast cancer display resistance to multiple chemotherapeutic drugs. Oncol Rep 35: 3293-3302, 2016.

6 Suyama K, Onishi H, Imaizumi A, Shinkai K, Umebayashi M, Kubo M, Mizuuchi Y, Oda Y, Tanaka M, Nakamura M and Katano M: CD24 suppresses malignant phenotype by downregulation of SHH transcription through STAT1 inhibition in breast cancer cells. Cancer Lett 374: 44-53, 2016.

7 Tanaka H, Nakamura M, Kameda C, Kubo M, Sato N, Kuroki S, Tanaka $\mathrm{M}$ and Katano $\mathrm{M}$. The Hedgehog signaling pathway plays an essential role in maintaining the $\mathrm{CD} 44^{+} \mathrm{CD} 24^{-/ \text {low }}$ subpopulation and the side population of breast cancer cells. Anticancer Res 29: 2147-2157, 2009.

8 He M, Fu Y, Yan Y, Xiao Q, Wu H, Yao W, Zhao H, Zhao L, Jiang Q, Yu Z, Jin F, Mi X, Wang E, Cui Z, Fu L, Chen J and Wei M: The Hedgehog signalling pathway mediates drug response of MCF-7 mammosphere cells in breast cancer patients. Clin Sci 129: 809-822, 2015.

9 Yang N, Zhou TC, Lei XX, Wang C, Yan M, Wang ZF, Liu W, Wang J, Ming KH, Wang BC, Xu BL and Liu Q: Inhibition of sonic hedgehog signaling pathway by thiazole antibiotic thiostrepton attenuates the CD44+/CD24- stem-like population and sphere-forming capacity in triple-negative breast cancer. Cell Physiol Biochem 38: 1157-1170, 2016.

10 Zhao H, Tang H, Xiao Q, He M, Zhao L, Fu Y, Wu H, Yu Z, Jiang Q, Yan Y, Jin F and Wei M: The Hedgehog signaling pathway is associated with poor prognosis in breast cancer patients with the $\mathrm{CD} 44^{+} / \mathrm{CD} 24^{-}$phenotype. Mol Med Rep 14: 5261-5270, 2016.

11 Dean M, Fojo T and Bates S: Tumour stem cells and drug resistance. Nat Rev Cancer 5: 275-284, 2005.

12 Bertolini G, Roz L, Perego P, Tortoreto M, Fontanella E, Gatti L, Pratesi G, Fabbri A, Andriani F, Tinelli S, Roz E, Caserini R, Lo Vullo S, Camerini T, Mariani L, Delia D, Calabrò E, Pastorino U, and Sozzi G: Highly tumorigenic lung cancer $\mathrm{CD} 33^{+}$cells display stem-like features and are spared by 
cisplatin treatment. Proc Natl Acad USA 106: 16281-16286, 2009.

13 Onishi H, Morifuji Y, Kai M, Suyama K, Iwasaki H and Katano M: Hedgehog inhibitor decreases chemosensitivity to 5fluorouracil and gemcitabine under hypoxic conditions in pancreatic cancer. Cancer Sci 103: 1272-1279, 2012.

14 Dean M, Rzhetsky A and Allikmets R: The human ATP-binding cassette (ABC) transporter superfamily. Genome Res 11: 11561166, 2001.

15 Schinkel AH, Smit JJ, van Tellingen O, Beijnen JH, Wagenaar E, van Deemter L, Mol CA, van der Valk MA, RobanusMaandag EC, te Riele HP, Berns AJ and Borst P: Disruption of the mouse Mdrla P-glycoprotein gene leads to a deficiency in the blood-brain barrier and to increased sensitivity to drugs. Cell 77: 491-502, 1994.
16 Hadnagy A, Gaboury L, Beaulieu R and Balicki D: SP analysis may be used to identify cancer stem cell populations. Exp Cell Res 312: 3701-3710, 2006.

17 Kaewpiboon C, Srisuttee R, Malilas W, Moon J, Oh S, Jeong HG, Johnston RN, Assavalapsakul W and Chung YH: Upregulation of STAT1-HDAC4 confers resistance to etoposide through enhanced multidrug resistance 1 expression in human A549 lung cancer cells. Mol Med Rep 11: 2315-2321, 2015.

Received November 18, 2016

Revised December 13, 2016

Accepted December 20, 2016 